\title{
Microanatomy, lipid peroxidation and
} antioxidant system of the visual cortex of rats following withdrawal from prolonged lead nitrate administration

\author{
Ahmad A. Tijani ${ }^{1}$, Damilare A. Adekomi ${ }^{2}$, Adedamola A. Fature ${ }^{3}$, Stephen O. Adewole ${ }^{4}$, Adedeji E. Adetunji ${ }^{3}$ \\ ${ }^{1}$ Department of Anatomy, Faculty of Basic Medical Sciences, College of Medicine, Ekiti State University, Ado-Ekiti, ${ }^{2}$ Department of Anatomy, Faculty of \\ Basic Medical Sciences, College of Health Sciences, Osun State University, Osogbo, ${ }^{3}$ Department of Anatomy, Faculty of Basic Medical Sciences, College \\ of Medical and Allied Health Sciences, Afe-Babalola University, Ado-Ekiti, ${ }^{4}$ Department of Anatomy and Cell Biology, Faculty of Basic Medical Sciences, \\ College of Health Sciences, Obafemi, Awolowo University, Ile-Ife, Nigeria
}

\begin{abstract}
Exposure to lead $(\mathrm{Pb})$ has been shown to alter the function of central nervous system and affect cholinergic neurons of the visual cortex in animal models. This study sought to investigate the withdrawal symptoms and oxidative stress on the visual cortex after lead exposure. A total of 20 healthy male Wistar rats were randomly divided into two groups $(\mathrm{n}=10)$ : group $\mathrm{A}$, control, received $10 \mathrm{ml} / \mathrm{kg}$ of distilled water for 30 days orally; group $\mathrm{B}$, lead treated group, received 10 $\mathrm{mg} / \mathrm{kg}$ of lead nitrate solution for 30 days orally. Group B was divided into two subgroups, group B1 serves as non-recovery while B2 serves as recovery (withdrawal). Five rats from each group were sacrificed under ether anesthesia 24 hours after the last oral administration of lead, while the remaining 5 rats (withdrawal subgroup) were sacrificed 30 days after the last oral administration of lead. The visual cortex was grossed from the brain tissue and processed for histology. Blood/serum samples were obtained and markers of oxidative stress (superoxide dismutase [SOD], catalase [CAT], glutathione peroxidase [GPX]), and lipid peroxidation (malondialdehyde [MDA]) were analyzed. Lead-exposed rats display a significant reduction in the SOD, CAT, and GPX level as well as increased in MDA level. However, following a recovery period, a non-significant improvement was seen in the histoarchitecture of the visual cortex.
\end{abstract}

Key words: Lead, Oxidative stress, Serum, Neurons

Received May 31, 2019; Revised July 10, 2019; Accepted September 16, 2019

\author{
Corresponding author: \\ Adedamola A. Fature (iD \\ Department of Anatomy, Faculty of Basic Medical Sciences, College of \\ Medical and Allied Health Sciences, Afe-Babalola University, Ado-Ekiti, \\ P.M.B 5454, Nigeria \\ Tel: +234-8069501996, E-mail: adedamolaf@abuad.edu.ng \\ Ahmad A. Tijani (iD \\ Department of Anatomy, Faculty of Basic Medical Sciences, College of \\ Medicine, Ekiti State University, Ado-Ekiti 360213, Nigeria \\ Tel: +234-8038063582, E-mail: tijani.adekilekun@eksu.edu.ng
}

\section{Introduction}

Lead $(\mathrm{Pb})$ is a natural component of the earth's crust and one of the environmental pollutants with unique properties such as softness, high malleability, ductility, low melting point that poses a major threat to human health in several aspects [1]. It is also a highly neurotoxic agent that causes brain damage, neurochemical dysfunction and severe behavioral problems [2]. It is widely distributed in the body and interferes with several biochemical processes by binding to sulfhydryl and other nucleophilic functional groups, thereby triggering some health problems and contributing to oxidative stress [3]. 
Lead is a persistent metal found in the air, water, soil and a variety of manufactured products like leaded gasoline, paints, ceramics, solders, water pipes, hair dye, cosmetics, airplanes, farm equipment, shielding for X-ray machines, etc. [4]. Lead is considered as a potent environmental toxin with nonbiodegradable nature and its toxic effects are well studied [5].

The visual cortex is the primary cortical region of the brain which plays a significant role in processing and transmission of visual information that is relayed from the retina. The primary visual cortex (V1) is located in the posterior pole of the occipital lobe, and it is the earliest cortical visual area which connects the middle stages and other late stages of visual structures [6, 7]. Many studies on the sensitivity of the visual system to neurotoxic substances, proposed that the use of different toxic agents alters the visual system [8]. Research has shown that the degeneration progress in retina disease model did not only affect the retina itself but also the visual cortex [8]. The harmful impacts of lead poisoning have been known since ancient times. Fox et al. (1982) [9] reported that specific irreversible impairments in the spatial resolution properties of the visual system following lead exposure were due to specific alterations in the retina, visual cortex and/or in the subcortical relay structures, the lateral geniculate nucleus and superior colliculus. However, some of the most severe consequences of exposure to this metal have only been described recently [8].

Becker et al. (2002) [10] reported that exposure to toxic metals and health effects of these toxic metals are manifested differently in males and females, due to differences in kinetics, mode of action, or susceptibility. In general, men have higher blood lead levels than women, mainly because of higher exposure, but also due to higher blood hematocrit levels, as lead in blood is bound to erythrocytes.

Lead affects the higher functions of the central nervous system and undermines brain growth, preventing the correct development of cognitive and behavioral functions [11]. This effect interferes with three major neurotransmission systems: the cholinergic, dopaminergic, and glutamatergic systems which are the neurotransmitters responsible for the regulation of motor coordination and emotion $[12,13]$. Previous studies indicate that moderate lead exposure has long term repercussions on the cholinergic visual system of adult rats and primate [14]. The ability of lead to gain access to the brain interstitial fluid is determined by the transport properties of a functional molecular barrier formed by brain capillary endothelial cells linked to one another by tight junctions (bloodbrain barrier). Lead uptake through this barrier proceeds consistently with its action as a potent central neurotoxin [15]. Reports have also shown that severe lead poisoning may compromise the barrier's integrity with significant abnormalities [16]. It has also been reported that lead induces oxidative stress by overproduction of free radicals, leading to cell membrane damage, via lipid peroxidation, which mediated the activation of inflammatory signaling cascades [17]. Lipid peroxidation is a deteriorative reaction that is involved in many disease processes and chemical toxicities concentrate in the brain. It is believed to be involved in several disease states, such as diabetes and neurodegenerative diseases as well as the aging process [18]. Deterioration of the photoreceptor cells, lateral geniculate nucleus, and superior colliculus can lead to progressive vision impairment and even total loss of sight which can also affect the visual cortex [8]. Hence, this study sought to investigate the withdrawal symptoms and oxidative stress on the visual cortex after lead exposure.

\section{Materials and Methods}

\section{Animal procurement, care, and maintenance}

Twenty adult male Wistar rats weighing between $130 \mathrm{~g}$ and $150 \mathrm{~g}$ (average weight of $140 \mathrm{~g}$ ) were procured from the animal holding of the College of Health Sciences, Obafemi Awolowo University, Ile-Ife. Standard rat pellet was purchased at once from Topawo Feeds Ltd., Osogbo to avoid change in ration of the animals in the course of the research work. The rats were housed in plastic cages in the animal holding of the Department of Anatomy and Cell Biology. They were maintained on standard laboratory rat pellets and given water ad libitum. They received humane care according to the guidelines of the Health Research Ethics Committee (HREC) of the Institute of Public Health (IPH), Obafemi Awolowo University, Ile-Ife.

\section{Procurement and preparation of lead nitrate $\left(\mathrm{PbNO}_{3}\right)$ solution}

Five hundred gramsof lead nitrate was procured from KADLAD (Nig) Ltd. (Osogbo, Nigeria). One point four grams of $\mathrm{PbNO}_{3}$ was weighed and dissolved in 11 of distilled water to form $1.4 \mathrm{mg} / \mathrm{ml}$ of $\mathrm{PbNO}_{3}$ solution. Preparation of $\mathrm{PbNO}_{3}$ solution was based on daily dose of $10 \mathrm{mg} / \mathrm{kg}$ given to each animal, which was an average daily dose of $1.4 \mathrm{mg}$ per animal.

\section{Research ethical approval}

Ethical clearance for the research was obtained from HREC 
of the IPH, Obafemi Awolowo University, Ile-Ife, Nigeria.

\section{Experimental design and administration}

The 20 rats were randomly assigned into two groups (A and B) of 10 rats each. Group A was the control group and animals in it received $10 \mathrm{ml} / \mathrm{kg}$ of distilled water for 30 days. Group B was the experimental group and animals in it received $10 \mathrm{mg} / \mathrm{kg}$ of lead nitrate solution for 30 days. All administrations were oral.

\section{Animal sacrifice, collection of blood samples, surgical removal, and fixation of organs}

Five rats from each group were sacrificed under ether anesthesia 24 hours after the last oral administration of lead, while the remaining 5 rats (withdrawal subgroup) were sacrificed 30 days after the last oral administration of lead. Their blood samples were obtained by cardiac puncture, transferred into separate plain bottles and centrifuged for 5 minutes at 4,000 rpm to obtain serum, in which markers of oxidative stress (superoxide dismutase [SOD], catalase [CAT], glutathione peroxidase $[\mathrm{GPX}]$ ) and lipid peroxidation (malondialdehyde [MDA]) were analyzed. Each whole animal was fixed in 10\% neutral buffered formalin using the standard intracardiac perfusion method of Gage et al. (2012) [19] as modified by Tijani et al. (2015) [20] for this study to dissect out the visual cortex for further processing according to the general technique of tissue processing and microtomy as described by Anderson and Bancroft (2002) [21].

\section{Metal analysis}

Blood was collected in plain bottles using heart puncture with a sterile syringe. After centrifugation at 4,000 $\times \mathrm{g}$ for 5 minutes at $4^{\circ} \mathrm{C}$, the serum blood was collected. Samples were analyzed for metal (lead level) by inductively coupled plasma mass spectrometry in the trace metals laboratory of Ekiti State University, Ado-Ekiti, Nigeria.

\section{Tissue processing, microtomy, and staining}

Following fixation, the tissues were processed for paraffin wax embedding. Small blocks of tissue about 3-5 mm thick were taken from visual cortex. The tissue blocks were dehydrated through ascending grades of alcohol by immersion and were infiltrated in two changes of molten paraffin wax at $56^{\circ} \mathrm{C}$ for one hour each before being finally embedded in paraffin wax using tissue cassette moulds. Paraffin blocked tissues were trimmed and sectioned on a rotary Leica microtome. Sections of $5 \mu \mathrm{m}$ thick were placed on clean glass slides and dried on a drying plate at a temperature of $40^{\circ} \mathrm{C}$ overnight to enhance adherence. The sections were stored in slide racks until ready for staining. Pearse procedure for hematoxylin and eosin staining as described by Bancroft and Gamble (2002) [22] was adopted.

\section{Microscopy and statistical analysis}

All sections were studied under Leica DM 750 microscope connected to a digital camera (Leica ICC 50) and a computer. Photomicrographs of stained sections were obtained, reported and imported into Image image analysis software (a National Institute of Health [NIH], USA sponsored software) for analysis. The data obtained was analyzed using a computerized statistical package (SPSS version 21, IBM Corp., Armonk, NY, USA) and Microsoft Office Excel 2007. One-way ANOVA was used to compare the mean and standard error of mean values within and between groups of experimental animals, followed by Student Newman-Keuls (SNK) test for multiple comparisons and determination of the significant differences between these mean values. Probability values less than 0.05 were considered statistically significant.

\section{Results}

\section{Analysis of biochemical parameters}

The serum lead, antioxidant activity, and lipid peroxidation were determined in all groups of animals and values presented as mean \pm SEM in Table 1. One-way analysis of variance

Table 1. Descriptive analysis of serum lead, antioxidant enzyme activity, and lipid peroxidation of rats with prolonged lead exposure

\begin{tabular}{|c|c|c|c|c|c|c|}
\hline Group & No. & Lead $(\mathrm{Pb})$ & SOD & CAT & GPX & MDA \\
\hline A1 & 5 & $1.608 \pm 0.014$ & $103.624 \pm 0.269$ & $6.426 \pm 0.392$ & $149.382 \pm 1.281$ & $3.134 \pm 0.051$ \\
\hline A2 & 5 & $1.622 \pm 0.013$ & $103.1160 \pm 0.134$ & $6.314 \pm 0.217$ & $149.594 \pm 1.443$ & $3.124 \pm 0.074$ \\
\hline B1 & 5 & $5.704 \pm 0.126^{\mathrm{a})}$ & $95.6280 \pm 0.325^{a)}$ & $4.840 \pm 0.161^{\text {a) }}$ & $133.082 \pm 1.053^{\mathrm{a})}$ & $3.804 \pm 0.042^{\mathrm{a}}$ \\
\hline B2 & 5 & $4.326 \pm 0.067^{\mathrm{a}, \mathrm{b})}$ & $96.1940 \pm 0.472^{\mathrm{a})}$ & $4.758 \pm 0.112^{\mathrm{a})}$ & $133.338 \pm 1.111^{\mathrm{a})}$ & $3.868 \pm 0.044^{\mathrm{a}}$ \\
\hline
\end{tabular}

SOD, superoxide dismutase; CAT, catalase; GPX, glutathione peroxidase; MDA, malondialdehyde. ${ }^{\text {a) }}$ Significantly different from control group (A1) at $P<0.05 .{ }^{\text {b) }}$ Significantly different from experimental group (B1) at $P<0.05$. 
Table 2. One-way ANOVA for serum lead, SOD, catalase, GPX, and MDA of rats with prolonged lead exposure

\begin{tabular}{|c|c|c|c|c|c|}
\hline & $\begin{array}{l}\text { Sum of } \\
\text { squares }\end{array}$ & $D f$ & $\begin{array}{l}\text { Mean } \\
\text { square }\end{array}$ & $F$ & $P$-value \\
\hline \multicolumn{6}{|l|}{ Lead } \\
\hline Between groups & 83.628 & 4 & 9.292 & 295.557 & $<0.05$ \\
\hline Within groups & 1.258 & 15 & 0.031 & & \\
\hline Total & 84.886 & 19 & & & \\
\hline \multicolumn{6}{|l|}{ SOD } \\
\hline Between groups & 401.780 & 4 & 44.642 & 50.490 & $<0.05$ \\
\hline Within groups & 35.367 & 15 & 0.884 & & \\
\hline Total & 437.147 & 19 & & & \\
\hline \multicolumn{6}{|l|}{ CAT } \\
\hline Between groups & 21.301 & 4 & 2.367 & 12.038 & $<0.05$ \\
\hline Within groups & 7.865 & 15 & 0.197 & & \\
\hline Total & 29.166 & 19 & & & \\
\hline \multicolumn{6}{|l|}{ GPX } \\
\hline Between groups & 2525.434 & 4 & 280.604 & 34.316 & $<0.05$ \\
\hline Within groups & 327.081 & 15 & 8.177 & & \\
\hline Total & 2852.515 & 19 & & & \\
\hline \multicolumn{6}{|l|}{ MDA } \\
\hline Between groups & 4.837 & 4 & 0.537 & 20.718 & $<0.05$ \\
\hline Within groups & 1.038 & 14 & 0.026 & & \\
\hline Total & 5.874 & 19 & & & \\
\hline
\end{tabular}

(ANOVA) of the mean values (Table 2) revealed that there were statistically significant differences in the mean values of the biochemical markers (lead, SOD, CAT, GPX, and MDA) between groups of animals and within each group of animals $(P<0.001)$. Homogenous categorization of the various mean values for the groups of animals and the different biochemical parameters was performed to compare the multiple groups of animals using SNK's post hoc tests for alpha of 0.05 .

\section{Serum lead}

The post hoc test categorized the four groups of animals into three subsets for serum lead levels (Table 3, Fig. 1). Group B1 animals have a mean value that was significantly different from mean values of other groups of animals, categorized alone in a subset. Similarly, mean value of group B2 animals is significantly different from other values, though less than that of group B1 animals. Groups A1 and A2 are in the same category with no significant difference between their mean values. Statistically significant differences exist between the different categories.
Table 3. Student-Newman-Keuls for serum lead, SOD, catalase, GPX, and MDA of rats with prolonged lead exposure

\begin{tabular}{|c|c|c|c|c|}
\hline \multirow[t]{2}{*}{ Group } & \multirow[t]{2}{*}{ No. } & \multicolumn{3}{|c|}{$\begin{array}{l}\text { Student-Newman-Keuls for SOD of rats } \\
\text { with prolonged lead exposure } \\
\text { Subset for alpha }=0.05\end{array}$} \\
\hline & & 1 & 2 & 3 \\
\hline \multicolumn{5}{|l|}{ Lead } \\
\hline $\mathrm{A} 1$ & 5 & 1.6080 & - & - \\
\hline A2 & 5 & 1.6220 & - & - \\
\hline B2 & 5 & 0.129 & 4.3260 & - \\
\hline B1 & 5 & - & - & 5.7040 \\
\hline$P$-value & & - & $<0.05$ & $<0.05$ \\
\hline \multicolumn{5}{|l|}{ SOD } \\
\hline B1 & 5 & 95.6280 & - & - \\
\hline B2 & 5 & 96.1940 & - & - \\
\hline A2 & 5 & - & 103.1160 & - \\
\hline $\mathrm{Al}$ & 5 & - & 103.6240 & - \\
\hline$P$-value & & 0.347 & 0.518 & - \\
\hline \multicolumn{5}{|l|}{ Catalase } \\
\hline B2 & 5 & 4.7580 & - & - \\
\hline B1 & 5 & 4.8400 & - & - \\
\hline $\mathrm{A} 2$ & 5 & - & 6.3140 & - \\
\hline $\mathrm{Al}$ & 5 & - & 6.4260 & - \\
\hline$P$-value & & 0.771 & 0.118 & - \\
\hline \multicolumn{5}{|l|}{ GPX } \\
\hline B1 & 5 & 133.0820 & - & - \\
\hline B2 & 5 & 133.3380 & - & - \\
\hline $\mathrm{A} 1$ & 5 & - & 149.3820 & - \\
\hline $\mathrm{A} 1$ & 5 & - & 149.5940 & - \\
\hline$P$-value & & 0.888 & 0.555 & - \\
\hline \multicolumn{5}{|l|}{ MDA } \\
\hline A2 & 5 & 3.1240 & - & - \\
\hline $\mathrm{Al}$ & 5 & 3.1340 & - & - \\
\hline B1 & 5 & - & 3.8040 & - \\
\hline B2 & 5 & - & 3.8680 & - \\
\hline$P$-value & & 0.827 & 0.533 & - \\
\hline
\end{tabular}

Means for groups in homogeneous subsets are displayed, uses harmonic mean sample size $=5.000$.

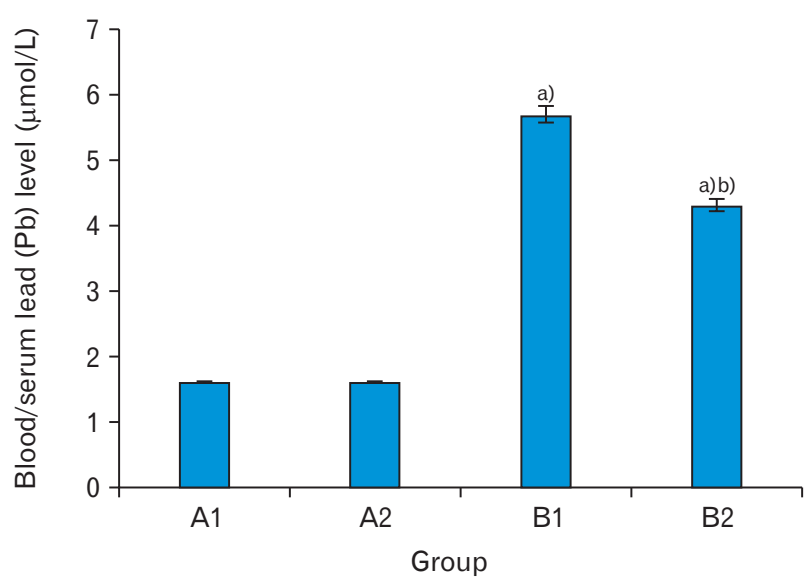

Fig. 1. Graph showing serum lead $(\mathrm{Pb})$ levels in rats treated with prolonged lead exposure. Results presented as mean \pm SEM $(n=5)$. A, control; B, experimental (lead treated); 1 , non-recovery; 2 , recovery. ${ }^{\text {a) }}$ Significantly different from positive control (A1) at $P<0.05 .{ }^{\text {b) }}$ Significantly different from negative control (B1) at $P<0.05$. 


\section{Serum SOD}

The four groups of animals were categorized into two subsets for serum SOD (Table 3, Fig. 2). There were statistically significant differences in the mean values between the categories of animals but no significant differences within each category. Groups of animals (B1 and B2) treated with lead nitrate have significantly reduced serum level of SOD. The difference in the values for group B1 and B2 is determined to be insignificant statistically.

\section{Catalase}

Serum CAT determination categorized the four groups of animals into two subsets (Table 3, Fig. 3) with the two sub-

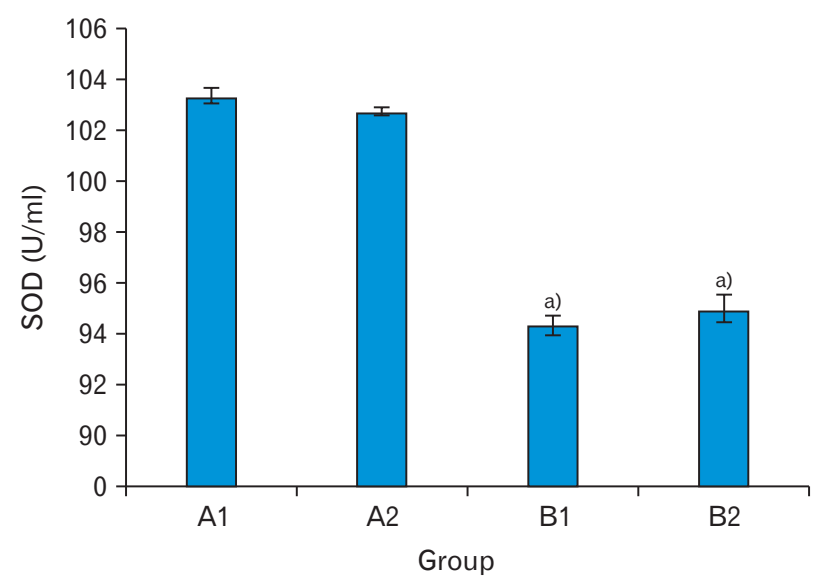

Fig. 2. Serum superoxide dismutase (SOD) levels in rats treated with prolonged lead exposure. Results presented as mean \pm SEM ( $n=5)$. A, control; B, experimental (lead treated); 1 , non-recovery; 2 , recovery. ${ }^{\text {a) }}$ Significantly different from positive control (A1) at $P<0.05$.

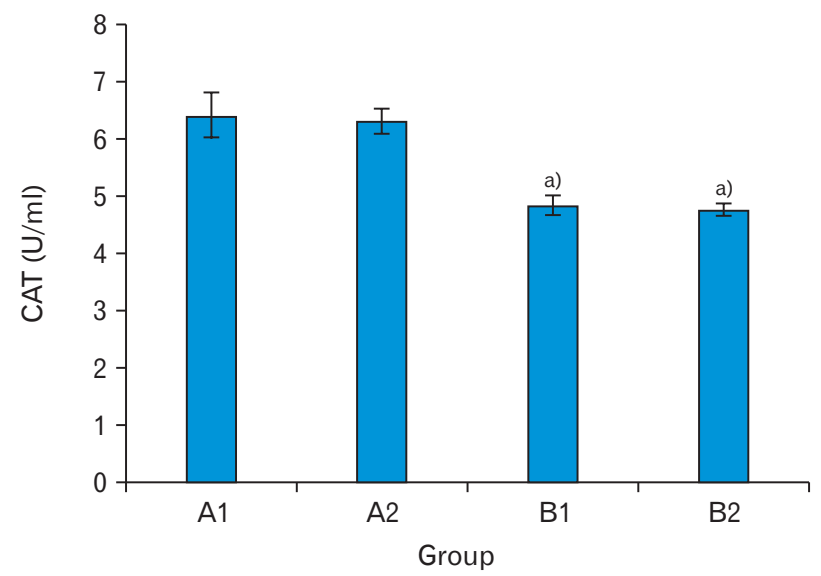

Fig. 3. Serum catalase (CAT) levels in rats treated with prolonged lead exposure. Results presented as mean $\pm \operatorname{SEM}(n=5)$. A, control; B, experimental (lead treated); 1 , non-recovery; 2 , recovery. ${ }^{\text {a) }}$ Significantly different from positive control (A1) at $P<0.05$. groups exposed to lead being in one subset and the two other subgroups in another subset. The mean values of groups B2 and $\mathrm{B} 1$ were not significantly different from each other but each of the two is very significantly lower as compared to values for other groups of animals.

\section{Glutathione peroxidase}

The post hoc test categorized the four groups of animals into two homogenous subsets for mean values of GPX (Table 3, Fig. 4). Lead-exposed groups, with or without recovery have significant difference in their mean values but expressed significantly lower level of GPX when compared with the control groups of animals. The control groups of animals have different mean values of GPX

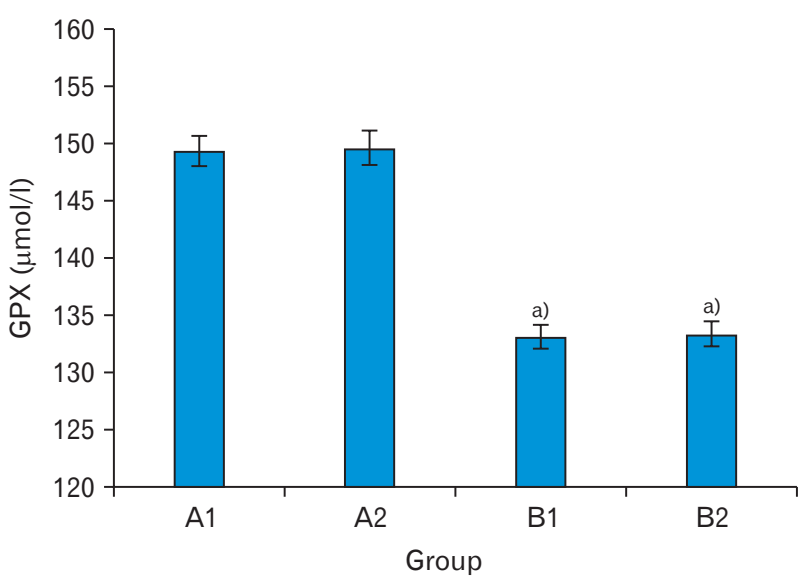

Fig. 4. Serum glutathione peroxidase (GPX) levels in rats treated with prolonged lead exposure. Results presented as mean \pm SEM $(n=5)$. A, control; B, experimental (lead treated); 1 , non-recovery; 2, recovery. ${ }^{\text {a) }}$ Significantly different from positive control (A1) at $P<0.05$.

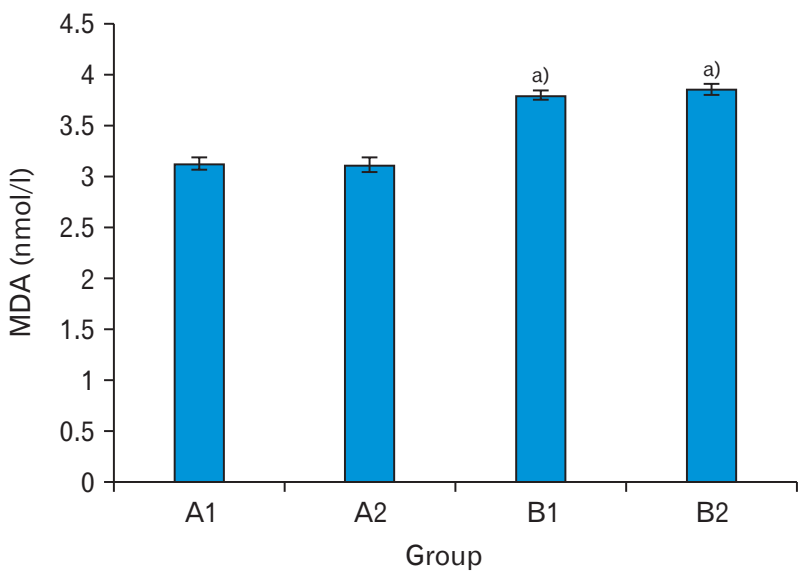

Fig. 5. Serum malondialdehyde (MDA) levels in rats treated with prolonged lead exposure. Results presented as mean $\pm \operatorname{SEM}(n=5)$. A, control; B, experimental (lead treated); 1 , non-recovery; 2 , recovery. ${ }^{\text {a) }}$ Significantly different from positive control (A1) at $P<0.05$. 
which are not significantly different from one another.

\section{Malondialdehyde}

Serum MDA was also homogenously categorized into two subsets with the post hoc test for multiple group comparison of mean values (Fig. 5). Groups of animals exposed to lead with or without recovery expressed statistically significantly different serum level of MDA when they were compared with the control group. Their values (B1 and B2) though differently expressed, have no significance in the difference. All other groups express different values that are not significant.

\section{Microanatomical study}

Sections of the visual cortex were critically examined under light microscope and were appropriately reported. Histological sections stained with hematoxylin and eosin obtained from the experimental group of animals (sections B1 and B2 in Plate 1) appeared equally heterogeneous and showed fine vacuoles in the neuropil around some neurons (Fig. 6). Cytoarchitecture of the neurons in these sections of experimental animals showed different stages of neuronal degeneration with variations in nuclear pyknosis, vacuolations, and cytoplasmic eosinophilia. Stained sections that were obtained from the control animals appeared seemingly normal with slightly eosinophilic neuropil and intact neurons.

\section{Discussion}

Exposure of the brain to excessive amounts of lead may impair neurotransmission, damage cellular materials, alters cellular genetics, Oxidative stress, and deregulation of cellular signaling, as a key aspect in neurotoxicity $[3,23]$. Lead accumulates in the brain even at low concentrations present in the environment and much of its neurotoxicity effect seem to be related to the dose duration of lead exposure as well as the age of the animal [24]. The present study supports the reports above because of the significant increase in the blood/serum level, antioxidant activity and lipid peroxidation observed in lead-exposed group.

To ascertain the adverse neurological effects being observed in human exposed to lead [25], higher concentration of lead was seen in the serum of rats in the non-recovery group (B1) when compare to the control group. A statistical increase was noticed in the recovery group when compared to the control but significantly different from the negative control. However, recovery group (withdrawal) is very active in modulating the concentration of serum lead level.

Oxidative stress is essentially an imbalance between the production of free radicals and the ability of the body to counteract or detoxify their harmful effects through neutralization by antioxidants. A significant reduction of serum SOD was observed in the recovery (B2) and non-recovery (B1) group when compared to the control animals $(P<0.05)$. In agreement with this, oxidative stress has been reported in dif-
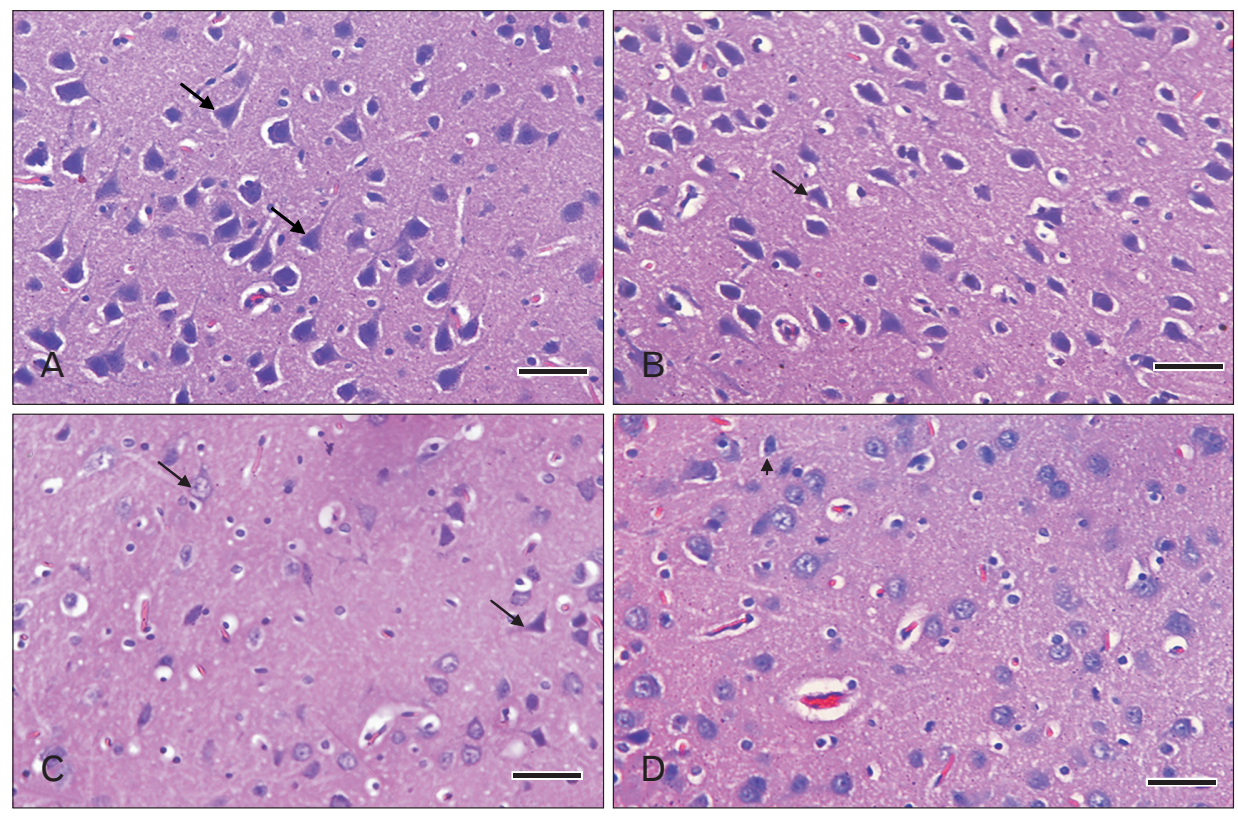

Fig. 6. Sections of visual cortex (H\&E, $\times 400)$ showing sections $\mathrm{A} 1(\mathrm{~A})$ and A2 (B) appearing normal with slightly eosinophilic neuropil and intact neurons. Sections B1 (C) and B2 (D) appear equally heterogeneous with fine vacuoles in the neuropil around some neurons. Neurons in sections B1 (C) and B2 (D) were seen in different stages of degeneration with variations in nuclear pyknosis and cytoplasmic eosinophilia and vacuolations. A, control; B, experimental (lead treated); 1 , non-recovery; 2, recovery. Arrow and arrowhead indicate intact neuron and degenerating neuron with pyknotic nucleus and cytoplasmic vacuolation/eosinophilia, respectively. Scale bars $=5 \mu \mathrm{m}(\mathrm{A}-\mathrm{D})$. 
ferent animal models as one of the important mechanisms of lead neurotoxicity [26].

In this study, we noticed an increased level of lipid peroxidation as shown by the higher MDA level and lower antioxidant enzymes in lead-exposed rats, compared to the control group. Glutathione is also an important compound for the detoxication and excretion of heavy metals. Increased MDA content, decease in CAT, and reduction of GPX were noted in lipid peroxidation from lead-exposed rats. These biochemical alterations in adult rats correlate with the deficits observed by Fox et al. (1982) [9] in a visual evoked cortical potential study. This also corroborates with the existing research that oxidative stress associated with lead exposure has been noted, and reported that lower total superoxide dismutase activity and higher MDA content were found in lead-exposed rat [26].

To demonstrate the general histoarchitecture of the visual cortex in this study, hematoxylin and eosin staining technique was used. The non-recovery group (B1) of animals shows a scantily distribution and destruction of the neuronal cells when compared to control, while the recovery group (B2) demonstrated an ameliorative role on the disrupted histoarchitecture of visual cortex. This finding is in support of Wang et al.s report (2016) [27], which suggested that the external stimulation could suppress the spontaneous hyperactivity in the visual cortex. In conclusion, the present results indicated that exposure of rats to lead might contribute to visual cortex impairment by causing a significant oxidative stress and disruption of the neuronal cells. Moreover, the withdrawing method can ameliorate the effect of lead toxicity.

\section{ORCID}

Ahmad A. Tijani: https://orcid.org/0000-0002-6735-1652

Damilare A. Adekomi:

https://orcid.org/0000-0002-7674-8168

Adedamola A. Fature:

https://orcid.org/0000-0002-6335-8793

Stephen O. Adewole:

https://orcid.org/0000-0003-1171-4933

Adedeji E. Adetunji:

https://orcid.org/0000-0003-0532-252X

\section{Author Contributions}

Conceptualization: AAT, DAA, AAF, SOA, AEA. Data acquisition: AAT, DAA, AAF, SOA, AEA. Data analysis or interpretation: AAT, DAA, AAF, SOA, AEA. Drafting of the manuscript: AAT, DAA, AAF, SOA, AEA. Critical revision of the manuscript: AAT, DAA, AAF, SOA, AEA. Approval of the final version of the manuscript: all authors.

\section{Conflicts of Interest}

No potential conflict of interest relevant to this article was reported.

\section{References}

1. Jacobs DE, Wilson J, Dixon SL, Smith J, Evens A. The relationship of housing and population health: a 30-year retrospective analysis. Environ Health Perspect 2009;117:597-604.

2. Flora SJ, Saxena G, Mehta A. Reversal of lead-induced neuronal apoptosis by chelation treatment in rats: role of reactive oxygen species and intracellular Ca2+. J Pharmacol Exp Ther 2007;322: 108-16.

3. Khan DA, Qayyum S, Saleem S, Khan FA. Lead-induced oxidative stress adversely affects health of the occupational workers. Toxicol Ind Health 2008;24:611-8.

4. Fortoul TI, Moncada-Hernández S, Saldivar-Osorio L, EspejelMaya G, Mussali-Galante P, del Carmen Avila-Casado M, ColínBarenque L, Hernández-Serrato MI, Avila-Costa MR. Sex differences in bronchiolar epithelium response after the inhalation of lead acetate $(\mathrm{Pb})$. Toxicology 2005;207:323-30.

5. Chen S, Miller TE, Golemboski KA, Dietert RR. Suppression of macrophage metabolite production by lead glutamate in vitro is reversed by meso-2,3-dimercaptosuccinic acid (DMSA). In Vitro Toxicol 1997;10:351-8.

6. Purves D, Augustine GJ, Fitzpatrick D, Hall WC, Lamantia AS, McNamara JO, Williams SM. Neuroscience. 3rd ed. Sunderland, MA: Sinauer Associates; 2004.

7. Bear MF, Connors BW, Paradiso MA. Neuroscience: exploring the brain. 4th ed. Philadelphia, PA: Wolters Kluwer; 2015.

8. Otto DA, Hudnell HK. The use of visual and chemosensory evoked potentials in environmental and occupational health. Environ Res 1993;62:159-71.

9. Fox DA, Wright AA, Costa LG. Visual acuity deficits following neonatal lead exposure: cholinergic interactions. Neurobehav Toxicol Teratol 1982;4:689-93.

10. Becker K, Kaus S, Krause C, Lepom P, Schulz C, Seiwert M, Seifert B. German Environmental Survey 1998 (GerES III): environmental pollutants in blood of the German population. Int J Hyg Environ Health 2002;205:297-308.

11. Marchetti C. Molecular targets of lead in brain neurotoxicity. Neurotox Res 2003;5:221-36.

12. Cory-Slechta DA. Relationships between lead-induced learning impairments and changes in dopaminergic, cholinergic, and glutamatergic neurotransmitter system functions. Annu Rev 
Pharmacol Toxicol 1995;35:391-415.

13. Nehru B, Sidhu P. Behavior and neurotoxic consequences of lead on rat brain followed by recovery. Biol Trace Elem Res 2001;84: 113-21.

14. Costa LG, Fox DA. A selective decrease of cholinergic muscarinic receptors in the visual cortex of adult rats following developmental lead exposure. Brain Res 1983;276:259-66.

15. Smith QR, Rabin O, Chikhale EG. Deliver of metals to brain and the role of the blood-brain barrier. In: Connor JR, editor. Metals and Oxidative Damage in Neurological Disorders. New York: Plenum Press; 1997. p.113-30.

16. Struzyńska L, Walski M, Gadamski R, Dabrowska-Bouta B, Rafałowska U. Lead-induced abnormalities in blood-brain barrier permeability in experimental chronic toxicity. Mol Chem Neuropathol 1997;31:207-24.

17. Zelikoff JT, Parsons E, Schlesinger RB. Inhalation of particulate lead oxide disrupts pulmonary macrophage-mediated functions important for host defense and tumor surveillance in the lung. Environ Res 1993;62:207-22.

18. Baynes JW. Role of oxidative stress in development of complications in diabetes. Diabetes 1991;40:405-12.

19. Gage GJ, Kipke DR, Shain W. Whole animal perfusion fixation for rodents. J Vis Exp 2012;(65):3564.

20. Tijani AA, Adekomi DA, Adewole OS. An improvised vascular perfusion apparatus for low resource histochemistry and immunohistochemistry laboratories. Ann Biol Res 2015;6:33-6.
21. Anderson G, Bancroft JD. Tissue processing and microtomy including frozen. In: Bancroft JD, Gamble M, editors. Theory and Practice of Histological Techniques. 5th ed. Edinburgh: Churchill Livingstone; 2002. p.85-107.

22. Bancroft JD, Gamble M. Theory and practice of histological techniques. 6th ed. Edinburgh: Churchill Livingstone; 2007. p. 744.

23. Antonio-García MT, Massó-Gonzalez EL. Toxic effects of perinatal lead exposure on the brain of rats: involvement of oxidative stress and the beneficial role of antioxidants. Food Chem Toxicol 2008;46:2089-95.

24. Kuhlmann AC, McGlothan JL, Guilarte TR. Developmental lead exposure causes spatial learning deficits in adult rats. Neurosci Lett 1997;233:101-4.

25. Rysz J, Banach M, Cialkowska-Rysz A, Stolarek R, Barylski M, Drozdz J, Okonski P. Blood serum levels of IL-2, IL-6, IL-8, TNFalpha and IL-1beta in patients on maintenance hemodialysis. Cell Mol Immunol 2006;3:151-4.

26. Wang Z, Wong A, Liu W, Yang J, Chu WC, Au L, Lau A, Chan A, Xiong Y, Soo Y, Leung T, Wong LK, Mok VC. Cerebral microbleeds and cognitive function in ischemic stroke or transient ischemic attack patients. Dement Geriatr Cogn Disord 2015;40: 130-6.

27. Wang Y, Chen K, Xu P, Ng TK, Chan LL. Spontaneous neural activity in the primary visual cortex of retinal degenerated rats. Neurosci Lett 2016;623:42-6. 